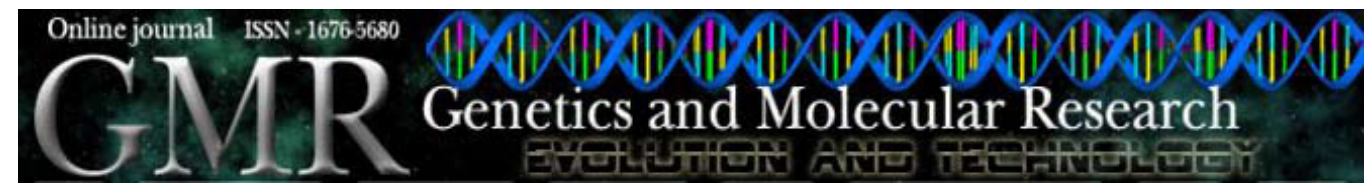

\title{
CCR2-64I is a risk factor for development of bladder cancer
}

\author{
K.F. Narter' , B. Agachan', S. Sozen², Z.B. Cincin² ${ }^{2}$ and T. Isbir ${ }^{2}$ \\ ${ }^{1}$ Department of Urology, Uskudar State Hospital, Istanbul, Turkey \\ ${ }^{2}$ Department of Molecular Medicine, Institute for Experimental Medicine, \\ Istanbul University, Istanbul, Turkey \\ Corresponding author: B. Agachan \\ E-mail: agachanb@yahoo.com
}

Genet. Mol. Res. 9 (2): 685-692 (2010)

Received January 15, 2009

Accepted February 17, 2010

Published April 13, 2010

DOI 10.4238/vol9-2gmr829

\begin{abstract}
Chemokines are potent proinflammatory cytokines that are implicated in numerous inflammatory diseases. Proinflammatory gene polymorphisms lead to variations in the production and concentration of inflammatory proteins. We investigated a possible association between polymorphisms in chemokine and chemokine receptor genes (MCP-1 A-2518G and CCR2-V64I) and bladder cancer risk. Genotypes were determined by PCR-RFLP assays in 72 bladder cancer patients and 76 unrelated age-matched healthy controls. There were significant differences in the frequencies of the MCP-1 A-2518G $(\mathrm{P}=0.012)$ and CCR2-V64I genotypes $(\mathrm{P}=0.004)$ between the controls and patients. The MCP-1 A-2518G GG genotype frequencies for controls and cases were 0.039 and 0.11 , respectively; individuals who had the GG genotype had a 3-fold increased risk of bladder cancer $(\mathrm{P}=0.08)$. The $\mathrm{CCR} 2-64 \mathrm{I} / 64 \mathrm{I}$ genotype frequencies for controls and cases were 0.02 and 0.13 , respectively; subjects carrying the 64I/64I genotype had a 5.9-fold increased risk of bladder cancer compared to the other genotypes. Individuals carrying the CCR2-V64I heterozygote or homozygous variant genotype (64I/64I + $\mathrm{wt} / 64 \mathrm{I}$ ) had a 2.9-fold increased risk of bladder cancer compared with the wild-type genotype (wt/wt). CCR2-V64I heterozygote or homozygous wild-type genotype $(\mathrm{wt} / \mathrm{wt}+\mathrm{wt} / 64 \mathrm{I})$ frequencies were significantly
\end{abstract}


decreased in the patient group compared with controls. We conclude that CCR2-64I is a new risk factor for bladder cancer.

Key words: Chemokines; MCP-1 A-2518G; CCR2-V64I; Polymorphism; Bladder cancer

\section{INTRODUCTION}

Bladder cancer is the fifth most common malignancy in Europe and the fourth most common malignancy in the United States (Jensen et al., 1990). Risk factors for the development of bladder cancer can be classified into three subsets; genetic and molecular abnormalities, chemical or environmental exposures, and chronic irritation (Kaufman et al., 2009).

Bladder cancer is closely associated with infection-induced inflammation. History of urinary tract infection significantly increases the risk of bladder cancer, especially in individuals who have three or more infections (Kantor et al., 1984). Chemokines are small, inducible proinflammatory cytokines, which are implicated in many biological processes, such as migration of leukocytes, embryogenesis, angiogenesis, hematopoiesis, atherosclerosis, tumor growth and metastasis, and HIV-infection (Mackay, 1997; Luster, 1998; Yoshie et al., 2001; Struyf et al., 2003; Vandercappellen et al., 2008). Four families of chemokines have been described based on the relative position of the conserved cystein residues, CC, CXC, XC, and CX3C. CCR, CXCR, XCR, and CX3CR are receptors that mediate the functions of these chemokines on their target cells. Many tumor cell types can express chemokines and chemokine receptors (Rollins, 1997; Rossi and Zlotnik, 2000; Vicari and Caux, 2002). CCL2 (MCP-1) is a member of the CC chemokine subfamily characterized by the absence of an amino acid between conserved cysteines at amino-terminal end of the molecule. The concentration gradient of CCL2 is responsible for the migration of mononuclear cells, mainly monocytes/macrophages, to sites of inflammation (Luster, 1998; Struyf et al., 2003; Navratilova, 2006). Several MCP-1 polymorphisms have been studied in relation to disease susceptibility or severity. The polymorphism A-2518G in the regulatory region of the MCP-1 gene influences MCP-1 expression in response to inflammatory stimuli (Rovin et al., 1999). CCR2 is a CC chemokine receptor that shows affinity for CCL2, CCL7, CCL8, and CCL13 ligands (Yoshie et al., 2001). CCR2 is mainly expressed by memory T lymphocytes, monocytes, dendritic cells, B cells, and basophils. The CCR2-64I mutation ( $\mathrm{G} \rightarrow$ A substitution at position 190 in the CCR2 chemokine receptor gene) results in a valine $\rightarrow$ isoleucine substitution at position 64 in the CCR2 protein (Smith et al., 1997; Kostrikis et al., 1998). In light of these findings, we aimed to determine whether genetic variants of chemokine CCR2-V64I receptor and its MCP-1 ligand are risk factors for bladder cancer.

\section{PATIENTS AND METHODS}

\section{Study groups}

The patient group consisted of 72 bladder cancer patients referred to Haydarpaşa $\mathrm{Nu}$ mune Hospital, Urology Department, aged between 28-86 years, and the control group consisted of 76 age-matched unrelated healthy subjects, 50-81 years old with no family history of bladder cancer. The control subjects were randomly selected among volunteer blood donors. Control subjects were not taking any regular medication at the time of the study. The bladder 
cancer patients were operated by transurethral resection or radical cystectomy.

Questionnaires, medical records and pathology reports were obtained to confirm the diagnosis and cancer status. All participants signed an informed consent form before enrollment, and the Institutional Ethics Committee approval was obtained for the study.

\section{Genotyping method of the CCR2-V64I and MCP-1 gene polymorphism}

Blood specimens were collected in tubes containing EDTA, and DNA was isolated from the leukocyte pellet by SDS lysis and ammonium acetate extraction followed by ethanol precipitation (Miller et al., 1988). CCR2-V64I and MCP-1 A-2518G genotypes were determined by the following previously published polymerase chain reaction (PCR) protocols (Szalai et al., 2001; Abdi et al., 2002): for the CCR2-V64I polymorphism, sense primer 5'-TTG GTT TTG TGG GCA ACA TGA TGG-3' and antisense primer 5'-CAT TGC ATT CCC AAA GAC CCA CTC-3'; for the MCP-1 A-2518G polymorphism, sense primer 5'-TCT CTC ACG CCA GCA CTG ACC-3' and antisense primer 5'-GAG TGT TCA CAT AGG CTT CTG-3' (Invitrogen, Carlsbad, CA, USA). The PCR mixture contained $100 \mathrm{ng}$ DNA template, $0.5 \mu \mathrm{M}$ of each primer, $1.5 \mathrm{mM} \mathrm{MgCl}, 2 \mathrm{mM}$ dNTPs (Invitrogen) and $1 \mathrm{U}$ Taq DNA polymerase (Intron Bio, Sungnam, Kyungki-Do, Korea). After denaturing the DNA for 5 min at $94^{\circ} \mathrm{C}$, the reaction mixture was subjected to 33 cycles of denaturing for $30 \mathrm{~s}$ at $94^{\circ} \mathrm{C}, 30 \mathrm{~s}$ annealing at $56^{\circ} \mathrm{C}$ and $30 \mathrm{~s}$ extension at $72^{\circ} \mathrm{C}$ for the CCR2-V64I. The 173-bp PCR product was digested with $8 \mathrm{U}$ $B s a \mathrm{BI}$ restriction endonuclease and the digested products separated by electrophoresis on a $3 \%$ agarose gel (UltraPure Agarose; Invitrogen, Carlsbad, CA) and visualized using ethidium bromide. The 64I/64I genotype contains a unique restriction site that results in 149- and 24-bp products, and the wt/wt genotype is not cut (173-bp), allowing the CCR2-V64I genotype to be determined.

For the MCP-1 A-2518G polymorphism, the reaction mixture was subjected to 35 cycles of denaturing for $45 \mathrm{~s}$ at $95^{\circ} \mathrm{C}, 45 \mathrm{~s}$ annealing at $52^{\circ} \mathrm{C}$ and $45 \mathrm{~s}$ extension at $72^{\circ} \mathrm{C}$. The PCR product (234 bp) was digested with $P v u I I$ (Invitrogen) and the digested products were separated and identified as above. Allele A did not contain the $P v u \mathrm{II}$ site whereas G contained the $P v u \mathrm{II}$ site, giving rise to 159 - and 75 -bp products. Each gel was read by two observers unaware of the subject's status. If there was any conflict, the reactions were repeated.

\section{Statistical analysis}

Statistical analyses were performed using the SPSS software package (revision 11.5 SPSS Inc., Chicago, IL, USA). Differences in the distribution of MCP-1 A-2518G and CCR2V64I genotypes or alleles between cases and controls were tested using the chi-square test. The Fisher exact test was used if the number in any cell of the $2 \times 2$ contingency table was $<5$. Relative risk at $95 \%$ confidence intervals (CI) was calculated as the odds ratio (OR). Comparisons of haplotype frequencies between patients and controls were carried out using the Haploview program (Barrett et al., 2005). After adjustment for age, to eliminate the confounding influences on bladder cancer, multivariate logistic regression analysis (forward:LR) was performed in which the study group was taken as the dependent variable and gender, smoking status, alcohol consumption, genotypes, and haplotypes were independent variables. Values of $\mathrm{P}<0.05$ were considered to be statistically significant. 


\section{RESULTS}

Controls and patients were adjusted for age. As expected, our patients were predominantly male. More smoker and alcohol consumers were represented in the cases as compared with the controls $(\mathrm{P}<0.001)$ (Table 1$)$.

\begin{tabular}{|c|c|c|c|}
\hline Parameter & Controls $(\mathrm{N}=76)$ & Patients $(\mathrm{N}=72)$ & $P$ \\
\hline Mean age (year) & $60.24 \pm 8.19$ & $63.48 \pm 11.70$ & NS \\
\hline Gender $(\%)$ (female/male) & $55.3 / 44.7$ & $18.1 / 81.9$ & 0.000 \\
\hline BMI $\left(\mathrm{kg} / \mathrm{m}^{2}\right)$ & $27.90 \pm 5.44$ & $26.10 \pm 2.81$ & NS \\
\hline Smoking status (\%) (yes/no) & $20.7 / 79.3$ & $67.7 / 32.3$ & 0.000 \\
\hline Alcohol consumption (\%) (yes/no) & $3.4 / 96.6$ & $30.8 / 69.2$ & 0.001 \\
\hline Grade $(1 / 2 / 3)$ & & $29 / 29 / 14$ & \\
\hline Stage (local/invasive) & & $28 / 44$ & \\
\hline $\begin{array}{l}\text { Pathologic type (adenocarcinoma/transitional } \\
\text { epithelial carcinoma) }\end{array}$ & & $3 / 69$ & \\
\hline
\end{tabular}

$\mathrm{BMI}=$ body mass index; $\mathrm{NS}=$ nonsignificant.

Table 2 shows the MCP-1 A-2518G and CCR2-V64I genotype frequencies among cases and controls. There were statistically significant differences in MCP-1 A-2518G $(\mathrm{P}=0.012)$ and CCR2-V64I genotypes $(\mathrm{P}=0.004)$ between the controls and patients. The MCP-1 A-2518G GG genotype frequencies for controls and cases were 0.039 and 0.11 , respectively, and individuals who had the GG genotype had a 3-fold increased risk of bladder cancer $\left(\mathrm{P}=0.08 ; \chi^{2}=2.7 ; \mathrm{OR}=\right.$ $3.04,95 \% \mathrm{CI}=0.77-11.9)$. MCP-1 A-2518G AG genotype frequency was significantly decreased in patients compared with controls $\left(\mathrm{P}=0.006 ; \chi^{2}=7.5 ; \mathrm{OR}=0.37 ; 95 \% \mathrm{CI}=0.18-0.76\right)$.

\begin{tabular}{|c|c|c|c|}
\hline Genotype/Allele & Controls (\%) & Patients (\%) & $\mathrm{P}$ \\
\hline \multicolumn{4}{|l|}{ MCP-1 A-2518G } \\
\hline AA & $40(52.6 \%)$ & $48(66.7 \%)$ & 0.082 \\
\hline GG & $3(3.9 \%)$ & $8(11.1 \%)$ & 0.097 \\
\hline $\mathrm{AG}$ & $33(43.4 \%)$ & $16(22.2 \%)$ & 0.006 \\
\hline A & $113(74.34 \%)$ & $112(77.7 \%)$ & \\
\hline G & $39(25.65 \%)$ & $32(22.2 \%)$ & 0.48 \\
\hline \multicolumn{4}{|l|}{ CCR2-V64I } \\
\hline $\mathrm{wt} / \mathrm{wt}$ & $59(77.6 \%)$ & $39(54.2 \%)$ & 0.003 \\
\hline $64 \mathrm{I} / 64 \mathrm{I}$ & $2(2.6 \%)$ & $10(13.9 \%)$ & 0.012 \\
\hline $\mathrm{wt} / 64 \mathrm{I}$ & $15(19.7 \%)$ & $23(31.9 \%)$ & 0.089 \\
\hline wt & $133(87.5 \%)$ & $101(70.1 \%)$ & \\
\hline 64I & $19(12.5 \%)$ & $43(29.86 \%)$ & 0.0002 \\
\hline
\end{tabular}

The CCR2-64I/64I genotype frequencies for controls and cases were 0.02 and 0.13 , respectively, and subjects carrying the 64I/64I genotype had a 5.9-fold increased risk of bladder cancer as compared to the other genotypes $(\mathrm{P}=0.012$; Fisher exact test; $\mathrm{OR}=5.96,95 \% \mathrm{CI}$ $=1.26-28.26)$. Individuals carrying the CCR2-V64I heterozygote or homozygous variant genotype $(64 \mathrm{I} / 64 \mathrm{I}+\mathrm{wt} / 64 \mathrm{I})$ had a 2.9 -fold increased risk of bladder cancer compared with the wild-type genotype $(\mathrm{wt} / \mathrm{wt})\left(\mathrm{P}=0.003 ; \chi^{2}=9.10 ; \mathrm{OR}=2.93 ; 95 \% \mathrm{CI}=1.44-5.98\right)$. CCR2V64I heterozygote or homozygous wild-type genotype $(\mathrm{wt} / \mathrm{wt}+\mathrm{wt} / 64 \mathrm{I})$ frequencies were significantly decreased in the patient group compared with controls $(\mathrm{P}=0.012$; Fisher exact test; $\mathrm{OR}=0.168 ; 95 \% \mathrm{CI}=0.03-0.79$ ). 
The control group was in Hardy-Weinberg equilibrium for both MCP-1 and CCR2 genotypes $(\mathrm{P}=0.22$ and $\mathrm{P}=0.39$, respectively), but the patient goup was not consistent with Hardy-Weinberg equilibrium for MCP-1 $(\mathrm{P}=0.002)$ and CCR2 $(\mathrm{P}=0.04)$ genotypes.

In addition to single nucleotide polymorphism analyses, haplotypes were evaluated for association with bladder cancer (Table 3). Haplotype analysis confirmed the association of MCP-1/CCR2 gene variants with bladder cancer and revealed that the frequencies of MCP-1 A:CCR2 64I haplotype was significantly different between patients and controls $(\mathrm{P}=0.0028)$.

\begin{tabular}{|c|c|c|c|c|c|c|}
\hline \multirow[t]{2}{*}{ Number of haplotype } & \multirow[t]{2}{*}{ Haplotype association } & \multicolumn{3}{|c|}{ Frequency } & \multirow[t]{2}{*}{ Chi-square } & \multirow[t]{2}{*}{$\mathrm{P}$} \\
\hline & & Overall & All patients & Control & & \\
\hline 1 & MCP-1 A:CCR2 wt & 0.587 & 0.535 & 0.630 & 2.901 & 0.0885 \\
\hline 2 & MCP-1 G:CCR2 wt & 0.205 & 0.166 & 0.238 & 2.485 & 0.115 \\
\hline 3 & MCP-1 A:CCR2 64I & 0.173 & 0.242 & 0.114 & 8.924 & 0.0028 \\
\hline 4 & MCP-1 G:CCR2 64I & 0.035 & 0.056 & 0.017 & 3.51 & 0.061 \\
\hline
\end{tabular}

While gender, smoking status, alcohol consumption, genotype (CCR-2 64I/64I) and haplotype (MCP-1 A:CCR2 64I) were associated with bladder cancer in univariate analysis, only gender and CCR-2 64I/64I genotype were associated with this disease in multivariate logistic regression analysis (Table 4).

\begin{tabular}{|c|c|c|c|c|c|}
\hline & & \multirow[t]{2}{*}{$\mathrm{P}$} & \multirow[t]{2}{*}{$\operatorname{Exp}(\mathrm{B})$} & \multicolumn{2}{|c|}{$95.0 \% \mathrm{CI}$ for $\operatorname{Exp}(\mathrm{B})$} \\
\hline & & & & Lower & Upper \\
\hline Step $1^{\mathrm{a}}$ & Gender & 0.000 & 17.729 & 4.650 & 67.603 \\
\hline \multirow[t]{2}{*}{ Step $2^{b}$} & Gender & 0.000 & 24.198 & 5.084 & 115.171 \\
\hline & CCR2 64I/64I & 0.027 & 13.716 & 1.351 & 139.248 \\
\hline \multirow[t]{3}{*}{ Step $3^{\mathrm{c}}$} & Alcohol use & 0.058 & 8.544 & 0.926 & 78.816 \\
\hline & Gender & 0.001 & 16.634 & 3.371 & 82.077 \\
\hline & CCR2 64I/64I & 0.024 & 14.229 & 1.427 & 141.879 \\
\hline
\end{tabular}

${ }^{a}$ Variable(s) entered on step 1: gender; ${ }^{b}$ Variable(s) entered on step 2: CCR2 64I/64I; ${ }^{\text {CVariable(s) entered on step }}$ 3: alcohol use.

We did not find any association between the distributions of genotypes or alleles in MCP-1 A-2518G and CCR2-V64I and the pathological types, stages and grades of the tumors $(\mathrm{P}>0.05)$ (Table 5).

Table 5. Distributions of genotypes in the patient group according to the pathological type, stage and grade of the tumors.

\begin{tabular}{|c|c|c|c|c|c|c|c|c|}
\hline & \multicolumn{4}{|c|}{ MCP-1 A-2518G } & \multicolumn{4}{|c|}{ CCR2-V64I } \\
\hline & AA & GG & AG & $\mathrm{P}$ & $\mathrm{wt} / \mathrm{wt}$ & $64 \mathrm{I} / 64 \mathrm{I}$ & $\mathrm{wt} / 64 \mathrm{I}$ & $\mathrm{P}$ \\
\hline \multicolumn{9}{|l|}{ Pathological type } \\
\hline Adenocarcinoma & $2(66.7 \%)$ & $0(0 \%)$ & $1(33.3 \%)$ & & $1(33.3 \%)$ & $0(0 \%)$ & $2(66.7 \%)$ & \\
\hline Transitional epithelial carcinoma & $46(66.7 \%)$ & $8(11.6 \%)$ & $15(21.7 \%)$ & NS & $38(55.1 \%)$ & $10(114.5 \%)$ & $21(30.4 \%)$ & NS \\
\hline \multicolumn{9}{|l|}{ Stage } \\
\hline Local & $17(60.7 \%)$ & $3(10.7 \%)$ & $8(28.6 \%)$ & & $14(50.0 \%)$ & $4(14.3 \%)$ & $10(35.7 \%)$ & \\
\hline Invasive & $31(70.5 \%)$ & $5(11.4 \%)$ & $8(18.2 \%)$ & NS & $25(56.8 \%)$ & $6(13.6 \%)$ & $13(29.5 \%)$ & NS \\
\hline \multicolumn{9}{|l|}{ Grade } \\
\hline Low grade & $17(58.6 \%)$ & $2(6.9 \%)$ & $10(34.5 \%)$ & & $15(51.7 \%)$ & $4(13.8 \%)$ & $10(34.5 \%)$ & \\
\hline High grade & $31(72.1 \%)$ & $6(14.0 \%)$ & $6(14.0 \%)$ & NS & $24(55.8 \%)$ & $6(14.0 \%)$ & $13(30.2 \%)$ & NS \\
\hline
\end{tabular}

Data are reported as number with percent in parentheses. NS $=$ nonsignificant. 


\section{DISCUSSION}

Chemokines and their receptors play diverse roles in malignant tumor progression, particularly as key mediators of tumor-stroma interactions (Balkwill, 2004; Karnoub and Weinberg, 2006). The current study is the first report showing that CCR2-64I is a risk factor for the development of bladder cancer. In the literature, there is only one report related to the polymorphic region of MCP-1 and CCR2 in bladder cancer. Vázquez-Lavista et al. (2009) found that the frequencies of the AA, GG and AG genotypes of the MCP-1 A-2518G gene are $14.29,29.37$ and 56.35, respectively, in the healthy control group and 19.15, 6.38 and 74.47, respectively, in the patient group. They showed a significant decrease in both the frequencies of the G mutant allele and the GG genotype in bladder cancer patients as compared with controls and suggested that MCP-1 polymorphism is associated with transitional cell carcinoma of the bladder in Mexican Mestizo patients. On the other hand, they did not find any difference in the polymorphism of CCR2-64I gene. Their CCR2-V64I wt/wt, wt/64I and 64I/64I genotype frequencies are 58.7, 34.13, 7.14 in the healthy control group and 59.5, 40.43 and 0.0 in the patient group, respectively, which are not in agreement with our results. The differences are attributable to ethnic differences.

Amann et al. (1998) showed that urinary levels of MCP-1 correlate with tumor stage and grade in patients with bladder cancer. They suggest that MCP-1 levels in the urine of patients with bladder cancer may be a prognostic marker for the natural course of the disease, and modulation of this chemokine may be a future therapeutic approach for adjuvant treatment of bladder cancer.

Although the CCR2-64I polymorphic variant has been reported to be protective in the development and progression of inflammatory diseases such as AIDS (Ioannidis et al., 2001; Mulherin et al., 2003), multiple sclerosis (Miyagishi et al., 2003), and development of breast cancer and cervical cancer (Zafiropoulos et al., 2004; Coelho et al., 2005), in our study this variant seems to be a risk factor for the development of bladder cancer.

Two isoforms of CCR2 are known, CCR2A and CCR2B, which are two transcripts that originate from the CCR2 gene by alternative splicing. These two isoforms differ only in the sequence of its C-terminal cytoplasmic tails, and CCR2A exists mainly in the cytoplasm while CCR2B migrates well to the cell surface (Nakayama et al., 2004). The level of expression of CCR2A-64I was significantly higher than that of CCR2A without the substitution. On the other hand, the 64I substitution did not affect levels of CCR2B expression (Nakayama et al., 2004). There are a few examples in which a valine-to-isoleucine substitution can markedly alter the bioactivity of proteins (Dawson et al., 1996). Nakayama et al. (2004) suggest that valine-to-isoleucine substitution promotes the stability of the isoform CCR2A, increasing its half-life, but it has no influence on CCR2B stability. As macrophages express CCR2A and CCR2B, the increased stability of the CCR2A isoform resulting from the CCR2-64I polymorphism may lead to its accumulation at the surface of the cell or the activation stimulus that is required for the expression of CCR2A on the cell surface, interfering with CCR2B function (Nakayama et al., 2004). Coelho et al. (2005) suggest that this leads to a decrease in macrophage recruitment during the development of the tumor, thereby obstructing the process of tumor angiogenesis, which is essential to the development of neoplasia.

Recently, Ginestier et al. (2010) found that the chemokine IL-8 receptor, CXCR1, triggers breast cancer stem cell growth in response to inflammation and tissue damage. During chemotherapy, dying tumor cells produce IL-8, which causes cancer stem cells to replicate. 
CXCR1 blockade may provide a novel means of targeting breast cancer stem cells.

Gender was significantly different in our study groups. Males outnumbered females in our patient group. Previous studies have suggested that men develop bladder cancer nearly three to four times more than women, as in our results (Shariat et al., 2010).

In conclusion, our findings have suggest that CCR2-64I may be a risk factor for the development of bladder cancer. We speculate that CCR2 polymorphism increases the biological activity of the CCR2 receptor and that increased activity may increase the risk of bladder cancer development. Further studies with larger sample groups are necessary to clarify the role of this chemokine receptor in the natural history of bladder cancer.

\section{REFERENCES}

Abdi R, Tran TB, Sahagun-Ruiz A, Murphy PM, et al. (2002). Chemokine receptor polymorphism and risk of acute rejection in human renal transplantation. J. Am. Soc. Nephrol. 13: 754-758.

Amann B, Perabo FG, Wirger A, Hugenschmidt H, et al. (1998). Urinary levels of monocyte chemo-attractant protein-1 correlate with tumour stage and grade in patients with bladder cancer. Br. J. Urol. 82: 118-121.

Balkwill F (2004). Cancer and the chemokine network. Nat. Rev. Cancer 4: 540-550.

Barrett JC, Fry B, Maller J and Daly MJ (2005). Haploview: analysis and visualization of LD and haplotype maps. Bioinformatics 21: 263-265.

Coelho A, Matos A, Catarino R, Pinto D, et al. (2005). Protective role of the polymorphism CCR2-64I in the progression from squamous intraepithelial lesions to invasive cervical carcinoma. Gynecol. Oncol. 96: 760-764.

Dawson SJ, Morris PJ and Latchman DS (1996). A single amino acid change converts an inhibitory transcription factor into an activator. J. Biol. Chem. 271: 11631-11633.

Ginestier C, Liu S, Diebel ME, Korkaya H, et al. (2010). CXCR1 blockade selectively targets human breast cancer stem cells in vitro and in xenografts. J. Clin. Invest 120: 485-497.

Ioannidis JP, Rosenberg PS, Goedert JJ, Ashton LJ, et al. (2001). Effects of CCR5-Delta32, CCR2-64I, and SDF-1 3'A alleles on HIV-1 disease progression: An international meta-analysis of individual-patient data. Ann. Intern. Med. 135: $782-795$.

Jensen OM, Esteve J, Moller H and Renard H (1990). Cancer in the European Community and its member states. Eur. J. Cancer 26: 1167-1256.

Kantor AF, Hartge P, Hoover RN, Narayana AS, et al. (1984). Urinary tract infection and risk of bladder cancer. Am. J. Epidemiol. 119: 510-515.

Karnoub AE and Weinberg RA (2006). Chemokine networks and breast cancer metastasis. Breast Dis. 26: 75-85.

Kaufman DS, Shipley WU and Feldman AS (2009). Bladder cancer. Lancet 374: 239-249.

Kostrikis LG, Huang Y, Moore JP, Wolinsky SM, et al. (1998). A chemokine receptor CCR2 allele delays HIV-1 disease progression and is associated with a CCR5 promoter mutation. Nat. Med. 4: 350-353.

Luster AD (1998). Chemokines - chemotactic cytokines that mediate inflammation. N. Engl. J. Med. 338: 436-445.

Mackay CR (1997). Chemokines: what chemokine is that? Curr. Biol. 7: R384-R386.

Miller SA, Dykes DD and Polesky HF (1988). A simple salting out procedure for extracting DNA from human nucleated cells. Nucleic Acids Res. 16: 1215.

Miyagishi R, Niino M, Fukazawa T, Yabe I, et al. (2003). C-C chemokine receptor 2 gene polymorphism in Japanese patients with multiple sclerosis. J. Neuroimmunol. 145: 135-138.

Mulherin SA, O'Brien TR, Ioannidis JP, Goedert JJ, et al. (2003). Effects of CCR5-Delta32 and CCR2-64I alleles on HIV1 disease progression: the protection varies with duration of infection. AIDS 17: 377-387.

Nakayama EE, Tanaka Y, Nagai Y, Iwamoto A, et al. (2004). A CCR2-V64I polymorphism affects stability of CCR2A isoform. AIDS 18: 729-738.

Navratilova Z (2006). Polymorphisms in CCL2 \& CCL5 chemokines/chemokine receptors genes and their association with diseases. Biomed. Pap. Med. Fac. Univ. Palacky. Olomouc. Czech. Repub. 150: 191-204.

Rollins BJ (1997). Chemokines. Blood 90: 909-928.

Rossi D and Zlotnik A (2000). The biology of chemokines and their receptors. Annu. Rev. Immunol. 18: 217-242.

Rovin BH, Lu L and Saxena R (1999). A novel polymorphism in the MCP-1 gene regulatory region that influences MCP-1 expression. Biochem. Biophys. Res. Commun. 259: 344-348. 
Shariat SF, Sfakianos JP, Droller MJ, Karakiewicz PI, et al. (2010). The effect of age and gender on bladder cancer: a critical review of the literature. BJU Int. 105: 300-308.

Smith MW, Carrington M, Winkler C, Lomb D, et al. (1997). CCR2 chemokine receptor and AIDS progression. Nat. Med. 3: 1052-1053.

Struyf S, Proost P and Van Damme J (2003). Regulation of the immune response by the interaction of chemokines and proteases. Adv. Immunol. 81: 1-44.

Szalai C, Duba J, Prohaszka Z, Kalina A, et al. (2001). Involvement of polymorphisms in the chemokine system in the susceptibility for coronary artery disease (CAD). Coincidence of elevated Lp(a) and MCP-1 -2518 G/G genotype in CAD patients. Atherosclerosis 158: 233-239.

Vandercappellen J, Van Damme J and Struyf S (2008). The role of CXC chemokines and their receptors in cancer. Cancer Lett. 267: 226-244.

Vázquez-Lavista LG, Lima G, Gabilondo F and Llorente L (2009). Genetic association of monocyte chemoattractant protein 1 (MCP-1)-2518 polymorphism in Mexican patients with transitional cell carcinoma of the bladder. Urology 74: 414-418.

Vicari AP and Caux C (2002). Chemokines in cancer. Cytokine Growth Factor Rev. 13: 143-154.

Yoshie O, Imai T and Nomiyama H (2001). Chemokines in immunity. Adv. Immunol. 78: 57-110.

Zafiropoulos A, Crikas N, Passam AM and Spandidos DA (2004). Significant involvement of CCR2-64I and CXCL12-3a in the development of sporadic breast cancer. J. Med. Genet. 41: e59. 